\title{
Proposta para análise da psicoterapia pais-bebê: evidências de dois casos
}

\author{
Evanisa Helena Maio de Brum ${ }^{1}$ \\ Aline Grill Gomes ${ }^{2}$ \\ Cesar Augusto Piccinini ${ }^{3}$ \\ ${ }^{1}$ Universidade Federal do Rio Grande do Sul, RS, Brasil; Centro Universitário Cesmac, AL, Brasil \\ ${ }^{2}$ Universidade Federal do Rio Grande do Sul, RS, Brasil; Sociedade Psicanalítica de Porto Alegre - SPPA, RS, Brasil \\ ${ }^{3}$ Universidade Federal do Rio Grande do Sul, RS, Brasil
}

\begin{abstract}
A Psicoterapia Pais-Bebê (PPB) é uma intervenção utilizada no tratamento das relações iniciais pais-bebê. O presente estudo teve como objetivo apresentar uma proposta de avaliação do processo psicoterápico em PPB, com destaque para os mecanismos de mudança ao longo da psicoterapia. Foram investigadas as intervenções da terapeuta (1) para obter informações, (2) para informar o paciente, (3) de apoio, (4) de encenação e (5) de interpretação transgeracional; e, os insights (1) cognitivo, (2) afetivo, e (3) pragmático, associados às intervenções. Cada uma destas categorias foram ilustradas através das verbalizações de dois casos de atendimentos pai-mãe-bebê, em que as mães apresentavam depressão pós-parto. Evidências sugerem que a proposta para análise de psicoterapia pais-bebê apresentada neste estudo pode contribuir para analisar o processo terapêutico.
\end{abstract}

Resumo

Palavras-chave: Psicoterapia pais-bebê; Processo psicoterápico; Intervenções terapêuticas; Insights.

\section{Proposal for the analysis of parents-infant psychotherapy: evidence of two cases}

\begin{abstract}
Parent-Infant Psychotherapy (PIP) represents an intervention used in the treatment of initial parent-infant relationships. Thus, the present study aimed to present a proposal for the evaluation of the psychotherapeutic process in PIP, with emphasis on the mechanisms of changing throughout psychotherapy. It was investigated the therapist's interventions (1) to collect information, (2) to inform the patient, (3) to give the support, (4) of staging and (5) transgenerational interpretation; e, the insights (1) cognitive, (2) affective, and (3) pragmatic associated with interventions. Each of these categories was illustrated through verbalizations of two father-mother-infant consultations, in which the mothers presented postpartum depression. Evidences suggest that the proposal for analysis of parent-infant psychotherapy presented in this study may contribute to analyze the therapeutic process.
\end{abstract}

Keywords: Parent-infant psychotherapy; Psychotherapy process; Therapeutic interventions; Insights.

\section{Propuesta para el análisis de la psicoterapia padres-bebé: evidencias de dos casos}

\section{Resumen}

La Psicoterapia Padres-Bebé (PPB) constituye una intervención utilizada en el tratamiento de las relaciones iniciales entre padres y bebé. De esta forma, el objetivo del presente estudio fue presentar una propuesta de evaluación del proceso psicoterápico en PPB, destacando los mecanismos de cambio a lo largo de la psicoterapia. Se investigaron las intervenciones del terapeuta (1) para la obtención de información, (2) para informar al paciente, (3) como soporte, (4) como puesta en escena y (5) para la interpretación transgeneracional; (1) cognitivo, (2) afectivo, y (3) pragmático, asociados a las intervenciones. Cada una de estas categorías fue ilustrada a través de las verbalizaciones de dos atendimientos padre-madre-bebé, en los que las madres manifestaban depresión posparto. Las evidencias sugieren que la propuesta para análisis de la psicoterapia padres-bebé presentada en este estudio, puede colaborar para analizar el proceso terapéutico.

Palabras clave: Psicoterapia padres-bebé; Evaluación; Proceso psicoterápico; Intervenciones terapéuticas; Insights. 


\section{Introdução}

A Psicoterapia Pais-Bebê (PPB) é um modelo de tratamento relativamente novo e se constitui em uma intervenção utilizada no tratamento dos distúrbios presentes nas relações iniciais entre a díade mãe-bebê ou a tríade pai-mãe-bebê (Guedeney et al., 2016). Atualmente encontramos diferentes formas de realizar a PPB, que podem ser classificadas em três tipos (Puura \& Kaukonen, 2010): 1) as psicodinamicamente orientadas que seguem os preceitos psicanalíticos e tem por objetivo intervir nas eventuais representações patológicas dos pais em relação ao bebê, desenvolvida por Cramer e Palácio-Espasa, com conceituações de Selma Fraiberg e Daniel Stern, entre outros teóricos; 2) as orientadas para as mudanças comportamentais da díade ou tríade e que incorpora os conceitos das terapias cognitivo-comportamentais, como proposto, por exemplo por Susan McDonough's; e, 3) as integrativas mãe-bebê, que integram as abordagens acima descritas, e podem ser exemplificada no trabalho de Alicia Lieberman, por exemplo. Neste artigo focaremos a PPB psicodinamicamente orientada descrita no item 1 da classificação acima, principalmente, nas formulações de Cramer e Palácio-Espasa (1993).

As pesquisas sobre PPB tem revelado que as díades ou tríades tiveram inúmeros benefícios quando envolvidas neste tipo de tratamento, como a melhora dos sintomas depressivos maternos (Cramer \& Stern, 1988; Goodman, et al., 2015; Lenze, Rodgers, \& Luby, 2015), dos sintomas psicofuncionais do bebê e da qualidade das interações pais-bebê (Goodman, et al., 2015; Chinitz et al., 2017); o aumento da sensibilidade materna (Cramer \& Stern, 1988; King, Priddis, \& Kane, 2014); a redução de apego inseguro (David \& Schiff, 2015; Guedeney et al., 2016); melhora no bem-estar do bebê (Chinitz et al., 2017), bem como alterações positivas nas representações maternas (Cramer \& Stern, 1988). Sabe-se que tais aspectos impactam positivamente o desenvolvimento infantil e, por conseguinte, a consitutição psíquica deste indíviduo em toda a sua vida. Com base nestes resultados a PPB tem sido indicada nos casos de distúrbios psicofuncionais, como de sono e alimentação, em angústias de separação, nos distúrbios de apego, nos distúrbios relacionais paisbebê (Cramer \& Palacio-Espasa, 1993) e nos casos de mães apresentando depressões desencadeadas pela condição da maternidade (Cramer \& Palacio-Espasa, 1993; Guedeney et al., 2016; Goodman, 2015).

Embora vários estudos apontem a importância da PPB como uma intervenção relevante, ainda são poucos os que se voltaram para a avaliação deste tipo de atendimento clínico. Além disso, a maioria destes avalia o resultado da psicoterapia na perspectiva dos estudos de eficácia (Goodman, et al., 2015; King, Priddis, \& Kane, 2014; Fonagy, et al., 2016; Salomonsson et, al., 2015; Toth et al., 2015; Chinitz et al., 2017; Prout et al., 2017) e poucos enfatizam o processo em si. Neste sentido, alguns pesquisadores defendem que somente o estudo do processo psicoterápico oferecerá respostas mais específicas sobre o impacto da psicoterapia nos tratamentos emocionais, buscando assim aprofundar aspectos que as pesquisas de resultado, que envolvem estudos de eficácia e efetividade, não alcançaram. Nesta direção, encontramos alguns estudos sobre psicoterapia com adultos que utilizaram abordagem qualitativa (Cassel, et al., 2015; Fishman, 2000; Goldfried \& Wolfe, 1996) e focaram os mecanismos de mudança em psicoterapia através de estudos de caso. Neste enfoque, tanto os momentos iniciais como finais da sessão ou do tratamento são levados em consideração, assim como todo processo entre esses dois momentos. Nesta abordagem, o objetivo é identificar e compreender os efeitos dos processos que levaram à mudanças terapêuticas ao longo de todo o tratamento (Fishman, 2000; Goldfried \& Wolfe, 1996) ou mesmo ao longo de uma sessão (Cassel et al., 2015). A questão dirigida por esta abordagem de investigação do processo psicoterápico é: "o que tem feito o psicoterapeuta para ter um impacto particular sobre o paciente?" (Goldfried \& Wolfe, 1996) com foco em pelo menos dois tipos de processos de mudanças: (a) indicações intra e interpessoais das mudanças dos pacientes; e (b) ações do terapeuta que tragam tais mudanças ao paciente.

Alguns autores, ainda no contexto da psicoterapia de adultos, também tem focado seus esforços na realização de pesquisas sobre episódios de mudança ou pontos de mudanças ${ }^{1}$ em psicoterapia (Váldes et al., 2005). Nesse sentido, trabalhar com pontos de mudanças é identificar e descrever exaustivamente os momentos que aparecem como significativos e relevantes para o processo de mudança, e mais especificamente o espaço de tempo entre os pontos, o segmento, e a sequência dentro de uma ou muitas sessões terapêuticas. Após o assinalamento desses pontos é realizada uma análise ampla tanto da relação das mudanças com os pontos anteriores à mudança, utilizando-se uma abordagem qualitativa, que trata de descobrir estes pontos e o que os compõem (Váldes et al., 2005).

Outra forma de estudar o processo terapêutico é através da análise dos ciclos de mudança, que

\footnotetext{
1 Autores utilizam os termos ponto de mudanças e episódios de mudanças como equivalentes.
} 
objetiva apresentar os momentos-chave de mudanças (relaxamento, experiência, reflexão e conexão) que são verificados através da presença de marcadores verbais de emoções e de processos de pensamentos no tratamento de adultos (Cassel et al., 2015). Nesta perspectiva temos, por exemplo, a proposta de Ferreira et al. (2015) que propõe que as sessões transcritas sejam analisadas momento-a-momento e fase-a-fase (avaliação, explicação, tratamento e consolidação). A ideia é compreender as mudanças que ocorrem em cada momento na sessão psicoterápica de adultos para explicar a transição entre as fases da psicoterapia, o que inclui a compreensão das intervenções terapêuticas.

Outra metodologia para avaliar o processo psicoterapêutico foi desenvolvida por Waldron et al. (2015) que criaram o Consórcio de Pesquisa Qualitativa (CPQ), que envolve um banco de dados com sessões psicanalíticas de longa duração realizada com adultos e gravadas para posterior análise. O CPQ é uma organização independente sem fins lucrativos financiada pela Associação Psicanalítica Americana (APA). Este grupo tem também se dedicado a desenvolver instrumentos que avaliam processo terapêutico como a Escala de Processo Analítico e a Escala de Interação Dinâmica.

No contexto da PPB, o estudo pioneiro de Cramer e Stern (1988) se destaca por avaliar o processo psicoterápico e especificamente as intervenções do terapeuta. Nele o processo psicoterápico foi analisado através das interpretações do terapeuta e suas consequências no aumento da sensibilidade materna. Os autores relatam o caso de uma díade mãe-bebê suíça, submetida à $\mathrm{PPB}$, cujo bebê apresentava sintomas psicossomáticos recorrentes (dores abdominais, insônia, regurgitações, entre outros). A intervenção teve por objetivo examinar a correspondência entre os comportamentos da mãe e sua representação emocional acerca do bebê. Foram realizadas cinco sessões de psicoterapia com intervalo de duas semanas. As sessões foram gravadas em videotape e posteriormente avaliadas. Num primeiro momento os dados foram examinados qualitativamente objetivando estudar as variáveis interativas que correspondessem comportamentalmente às representações mentais inconscientes da mãe. Foram utilizados os seguintes critérios para identificar os temas de interação mãebebê: 1) O tema existiu na história de vida passada da mãe na forma de expectativas e memórias do seu núcleo conflitual; 2) O tema estava relacionado ao conteúdo mãe-criança; 3) O tema era encenado pela mãe na interação com seu bebê; 4) O tema interacional resultava na formação de sinais e sintomas no bebê. A partir destes quatro critérios os autores encontraram cinco temas interativos considerados patogênicos na relação mãe-bebê: 1) Medo da mãe de que seu corpo fosse danificado pelas agressões do bebê; 2) Evitação pela mãe de contato corporal e proximidade com o bebê; 3) Queixas da mãe de que seu filho não era apegado a ela; 4) Agressões da mãe dirigidas à criança; e, 5) Medo da mãe de ser passiva com o bebê e para isto precisar de um parceiro ativo. As mudanças comportamentais observadas em relação a cada tema foram apontadas ao longo do tratamento psicoterápico. Neste sentido, Cramer e Stern (1988) salientaram que como não foi possível mensurar as alterações no domínio representacional, verificou-se os efeitos das mudanças no domínio comportamental. Por fim, a análise quantitativa deste estudo de Cramer e Stern (1988) avaliou a responsividade materna antes e depois das interpretações do terapeuta. Foram investigadas 25 solicitações do bebê para sua mãe antes das interpretações e 25 solicitações depois das interpretações. Os resultados revelaram que as interpretações do terapeuta aumentaram a sensibilidade da mãe de $40 \%$ para $88 \%$, com resultado estatisticamente significativo.

Estudos brasileiros também tem sido realizados sobre processo psicoterápico em PPB, e alguns deles integraram um projeto sobre PPB e depressão pósparto $^{2}$. Configuram-se em estudos de casos qualitativos, nos quais a evolução em relação aos temas centrais conflituais apresentados são analisados ao longo de todas as sessões e apresentam uma análise mais geral, sem se nortear por pontos de mudança ocorridos a partir das intervenções do terapeuta. Por exemplo, o estudo de Schwengber (2006) analisou eventuais modificações nas representações acerca da maternidade em mães com indicadores de depressão submetidas a PPB. O estudo de Frizzo (2008) investigou as relações familiares no contexto de depressão pós-parto em duas famílias, especificamente os conceitos de conjugalidade e parentalidade. Já a importância da participação do pai na PPB foi destacada por Silva (2007). Gomes (2007) investigou o impacto da PPB para a constelação da maternidade em uma família em que a mãe estava deprimida e o bebê apresentava malformação cardíaca grave. O estudo de Alfaya (2006) avaliou o processo psicoterápico a partir de uma análise do comportamento exploratório do bebê e do comportamento da mãe. Por fim, o estudo de Brum (2010) investigou o processo terapêutico da PPB, [cujos resultados são parcialmente

\footnotetext{
2 Piccinini et al. (2003). "O impacto da psicoterapia para a depressão materna e para a interação pais-bebê: Estudo longitudinal do nascimento ao segundo ano de vida do bebê - PSICDEMA”. Instituto de Psicologia - UFRGS, Porto Alegre. Projeto de Pesquisa não publicado, apoiado com recursos do $\mathrm{CNPq}$.
} 
apresentado no presente artigo]. Todos esses estudos independentes dos seus achados específicos, apontaram para a importância da PPB no contexto da DPP.

Além dos estudos empíricos revisados acima, cabe destacar o estudo teórico de Barrows (2003) que propõe dois conceitos relacionados aos processos de mudança em PPB: a função continente e o insight transgeracional. Para o primeiro conceito o autor utilizou as formulações de Bion (1962), que referem-se à função continente da mãe, ao acolher e conter as necessidades e angústias projetadas pelo bebê através do mecanismo de identificação projetiva. No setting terapêutico o terapeuta precisa também funcionar como uma figura continente para dar conta das identificações projetivas do paciente. Relacionada à função de continência, podemos apontar também para a importância do holding na relação paciente-terapeuta (Winnicott, 1956/2000) que é a capacidade da mãe de fornecer ao bebê o necessário suporte egóico, tanto psíquico como físico. Através do holding o terapeuta realizaria, como a mãe, a função de sustentar, acolher e amparar o paciente, ajudando-o a integrar-se e a nomear sensações e sentimentos que o paciente ainda não está capaz de fazer por si. Em algumas situações no setting terapêutico o "simples" fato de o terapeuta acompanhar silenciosamente o paciente em sua fala, em seu silêncio, em suas descobertas e dores é considerado uma ação de holding (Winnicott, 1956/2000). O holding também pode ocorrer na sessão terapêutica através de intervenções de apoio, nas quais o terapeuta compreende, acolhe e ampara o paciente através de sua fala.

O segundo conceito apresentado por Barrows (2003), insight transgeracional, é obtido através das intervenções do terapeuta acerca dos processos transgeracionais. Para sua formulação o autor tomou como base as contribuições teóricas de Fraiberg, Adelson e Shapiro (1994) e de Lebovici (1993) que destacam que as psicopatologias podem ser impostas de uma geração à outra de forma inconsciente. Assim, a chegada de um bebê pode evocar inconscientemente o passado traumático dos pais e trazer os fantasmas para "o quarto do bebê" (Fraiberg et al., 1994; Lebovici, 1993). Portanto, o bebê pode carregar desde seu nascimento, ou até mesmo antes, o peso histórico das patologias dos pais. É como se o genitor estivesse condenado a repetir com seu bebê a tragédia de sua própria infância e a modificação da relação pais-bebê só pode ocorrer através da elaboração desta repetição e da intervenção de interpretação transgeracional destes conflitos inconscientes.

A investigação dos processos de mudança em PPB teve também uma importante sustentação teórica na ideia sobre encenação (enactment) (Lebovici, SolisPonton \& Menendez, 1995/2004), que se refere ao tipo de intervenção na qual o terapeuta comunica-se com os pais buscando colocar-se no lugar do bebê e falando pelo bebê. A comunicação é apresentada como sendo a fala e o sentimento do bebê e pode ocorrer tanto com o uso de palavras quanto de ações direcionadas ao bebê. Lebovici esclareceu que a encenação ocorre devido à capacidade empática do terapeuta, a qual denominou de empatia metaforizante. Salomonsson (2017) reforça a questão apontando para a importância da fala do terapeuta direcionada ao bebê em PPB, e nesse sentido destaca que: 1) Este direcionamento contém mais do que um mero fluxo de palavras lexicais e seus componentes não verbais; 2) O bebê presta atenção a um terapeuta que o atende, sendo capaz de perceber alterações emocionais no terapeuta; e, 3) O bebê se interessa por um terapeuta que procura falar a verdade sobre os conflitos relacionais dele com sua mãe.

Assim, percebe-se que as intervenções de interpretação transgeracional, apoio e encenação, se destacam na literatura que examina o processo de mudança em PPB e são apontadas como relevantes tanto em termos teóricos quanto pela sua aplicabilidade técnica em PPB. Porém, poucos foram os estudos encontrados com estas intervenções no contexto da PPB. Diante disso, e da ideia de Guedeney (2016) de que as intervenções terapêuticas utilizadas em PPB são basicamente as mesmas utilizadas na psicoterapia de orientação psicanalítica, para embasar o presente estudo, recorreu-se a estudos de intervenções terapêuticas no contexto de psicoterapia de adultos de orientação psicanalítica.

Por exemplo, em seu estudo sobre psicoterapia de orientação psicanalítica, Beutler e Larry (2013), referem, entre outras questões, que as intervenções de apoio são ações do terapeuta que transmitem credibilidade, calor, compreensão e aceitação, com o objetivo de estabelecer uma relação de confiança. Destacam que as pesquisas empíricas fornecem evidências sólidas de que os pacientes respondem positivamente a essas intervenções. Cabe também destacar o estudo de Despland et al. (2001) que focou a relação entre mecanismos de defesa dos pacientes, intervenções do terapeuta e o desenvolvimento de aliança terapêutica em pacientes canadenses que receberam sessões de psicoterapia psicodinâmica breve. As intervenções foram classificadas em três categorias: interpretativas, de apoio e definições terapêuticas. Os resultados revelaram que nenhum tipo de intervenção isolada influenciou a formação de aliança terapêutica. Entretanto, o grau de ajuste da intervenção do terapeuta ao nível de funcionamento 
defensivo do paciente influenciou de forma positiva o estabelecimento da aliança terapêutica.

Ainda no contexto de atendimento de adultos encontramos a proposta de Etchegoyen (1987) para classificação das intervenções terapêuticas. O autor refere que o analista tem a sua disposição materiais e instrumentos para realizar seu trabalho terapêutico, definindo materiais como as questões que surgem do paciente, e o analista trabalha sobre estes materiais com seus instrumentos, que são as diferentes formas de intervenção. $\mathrm{O}$ autor propõe que estas diferentes formas de intervenção terapêutica podem ser classificadas de três formas. A primeira refere-se às intervenções destinadas a influenciar o paciente, como apoio (quando o terapeuta apoia ou reforça algum comportamento ou sentimento do paciente); sugestão (quando o terapeuta sugere algo ao paciente) e, persuasão (quando o terapeuta troca ideias ou argumenta com o paciente tentando persuadi-lo). Etchegoyen (1987) também apontou que o uso de intervenções para influenciar o paciente é criticável, pois podem levá-lo à dependência do terapeuta e à processos de insegurança emocional. Contudo, referiu que se utilizadas adequadamente podem ser úteis em certas formas de psicoterapia, inclusive na psicanálise.

A segunda forma de classificação refere-se às intervenções destinadas a obter informação do paciente, e inclui assinalamento (quando o terapeuta chama a atenção para algo do discurso do paciente) e confrontação (quando o terapeuta confronta aspectos contraditórios da conduta, do sentimento ou do pensamento do paciente). A terceira delas refere-se às intervenções destinadas a informar o paciente e inclui interpretação (quando o terapeuta oferece alguma informação veraz, desinteressada e pertinente à realidade do paciente), esclarecimento (quando o terapeuta esclarece algo que o paciente disse, reordenando a informação) e, por fim a informação propriamente dita (quando o terapeuta oferece alguma informação ao paciente que traga elementos para compreensão da realidade). $\mathrm{O}$ autor destacou que as classificações das intervenções são úteis para os profissionais e pesquisadores da área, mas que, por vezes, na prática podem apresentar sobreposições. Considerando a proposta de Etchegoyen (1987), é plausível se pensar que possa também ser útil para fins de análise da PPB.

Outro tema a ser considerado se refere ao fato de que comumente os resultados das intervenções psicanalíticas com adultos são avaliados através de indicadores de mudança, tais como associação livre, aliança terapêutica, sintomas, mecanismos de defesa e insight. Entre eles o insight tem sido destacado como um importante indicador de mudanças (Sandell, 2015), que envolve a compreensão intelectual e emocional do paciente acerca dos seus padrões relacionais ou comportamentais, dos seus problemas, de sua origem e etiologia, bem como do seu significado. Portanto, o insight revela mudanças específicas ou gerais em alguns aspectos da dinâmica psíquica e/ou comportamental do paciente. Atualmente, embora os pesquisadores ainda acreditem ser muito difícil definir este termo na psicanálise, parece haver certo consenso que ele refere-se à compreensão pelo paciente de fatos dinâmicos que contribuem para a resolução de conflitos inconscientes (Sandell, 2015; Zimerman, 2001). Além disto, encontram-se na literatura diferentes formas de classificá-lo, sendo que duas grandes categorias de insights são citadas com maior frequência: os afetivos e os cognitivos (Sandell, 2015; Zimerman, 2001).

Uma forma de classificação mais específica é proposta por Zimerman (2001), que divide insight em cinco tipos. O primeiro deles denomina-se intelectivo e refere-se aos momentos em que o paciente obtém uma compreensão intelectualizada do material trabalhado. O autor criticou esta classificação por acreditar que uma compreensão intelectual não deveria ser acompanhada da palavra insight, e salientou que esta classificação é inócua e pode ser prejudicial nos casos de pacientes obsessivos e narcisistas que normalmente utilizam a intelectualização para reforçar seu arsenal defensivo. O segundo é denominado cognitivo, e diz respeito aos momentos em que o paciente toma claramente conhecimento de atitudes e características suas, que até então estavam egossintônicas. O terceiro, denominado de afetivo, se dá quando a compreensão do paciente sobre seu funcionamento dinâmico passa a ser acompanhada por vivências afetivas. Além disto, podem ocorrer insights afetivos parciais, que seriam os momentos em que o paciente se sente tocado pela intervenção, porém não chega a aprofundar sua compreensão sobre as questões apontadas pelo terapeuta. O quarto tipo denomina-se reflexivo, quando o paciente passa a refletir sobre as compreensões obtidas através dos insights afetivos. O quinto tipo de insight é denominado pragmático e refere-se às mudanças que aparecem na vida real da paciente e estão sob o controle do ego. Zimerman referiu que a classificação dos insights é importante para que os estudos em psicanálise avancem, contudo, destacou que ela pode ser, por vezes, didática, pois na prática clínica é difícil discernir os tipos de insights. Parece que esta dificuldade acentua-se quanto à classificação dos insights afetivos e reflexivos, pois o reflexivo surge como uma consequência do afetivo e pode ser difícil distingui-los na prática. 
Juntos, os estudos revisados acima sobre intervenções do terapeuta e insights revelam a escassez de trabalhos específicos sobre a classificação das intervenções do terapeuta e os insights associados a estas, particularmente em PPB. Dessa forma, salientamos a importância de se investigar o processo psicoterápico, especificamente através das intervenções do terapeuta e os indicadores de mudança associados a estas, por ser esta uma abordagem capaz de trazer conhecimentos que se aproximam da prática clínica, em particular daquela envolvendo a PPB.

\section{Analisando as intervenções e insights na PPB}

Com base nas ideias dos autores revisados acima, a primeira autora deste artigo propôs em seu doutorado uma forma de avaliar as intervenções da terapeuta em PPB e os insights associados à elas (Brum, 2010) ${ }^{3}$. Para tanto foi utilizado um delineamento de estudo de caso coletivo (Stake, 2006) para se investigar o processo psicoterápico dos dois casos atendidos em psicoterapia pais-bebê. As sessões com duração aproximada de 1 hora foram gravadas em áudio e vídeo e posteriormente transcritas. $\mathrm{Na}$ análise qualitativa foram utilizadas tanto as transcrições quanto as filmagens de todas as sessões, para considerar, dentro do possível, os conteúdos manifestos e latentes das verbalizações e das interações durante as sessões psicoterápicas. A análise foi composta de 4 etapas: 1) os vídeos das sessões foram assistidos e acompanhados pela transcrição das sessões [previamente realizadas], com o objetivo de compreender o caso e construir uma breve descrição do mesmo. 2) os vídeos das sessões foram assistidos novamente, acompanhados das transcrições objetivando realizar possíveis correções no material transcrito, bem como para descrever as manifestações não-verbais. 3) os vídeos das sessões foram assistidos pela terceira vez para destacar todas as intervenções da terapeuta e os insights e classificá-los nas categorias de análise propostas neste estudo. 4) por fim, com o material transcrito das sessões se investigou as associações entre as intervenções e os insights.

Ressalta-se também que os atendimentos do caso foram realizados por uma terapeuta com formação em psicanálise e em psicoterapia pais-bebê, com base na proposta de Cramer e Palácio-Espasa; já as análises dos casos foram realizadas pela primeira autora deste artigo, também terapeuta com formação psicanalítica. Essa escolha foi feita, pois o uso de avaliador independente tem sido destacado na literatura como um importante

\footnotetext{
3 Este estudo integrou o Projeto PSICDEMA mencionado anteriormente.
}

fator que aumenta a independência, a objetividade e o rigor metodológica nas análises realizadas (Fishman, 2000).

O estudo teve aprovação do comitê de ética em pesquisa da UFRGS (Protocolo 200396). O Caso 1 é o de uma família composta pelo pai Ricardo (36 anos), pela mãe Luana (32 anos), que apresentava DPP, e o bebê Jeferson (11 meses). O casal vivia em união estável há 4 anos, quando o atendimento em PPB aconteceu e durou 16 sessões. Ricardo tinha também outro filho, Pedro ( 9 anos), de seu primeiro casamento. Já no Caso 2 participou uma família composta pela mãe Helena (48 anos), com DPP, e o pai Adriano (52 anos), casados há 31 anos quando o filho Lucas (2 meses) nasceu. $\mathrm{O}$ casal tinha mais três filhos de 20, 29 e 31 anos, todos casados e não residiam com os pais. O casal e o bebê foram atendidos durante 12 sessões. Apresenta-se a seguir a proposta de avaliação das intervenções da terapeuta com relatos ${ }^{4}$ dos casos, que exemplificam as intervenções e os insights ligados à elas.

Com base na revisão de literatura acima exposta (Barrows, 2003; Etchegoyen 1987; Lebovici, et. al., 1995/2004), as intervenções da terapeuta na PPB são aqui definidas como todas as suas verbalizações e ações direcionadas à díade mãe-bebê, ou à tríade paimãe-bebê, ao bebê ou ao casal, durante as sessões. As intervenções da terapeuta foram classificadas em cinco categorias, a saber: 1) intervenções para obter informações; 2) intervenções utilizadas para informar o paciente; 3) intervenções de apoio; 4) intervenções de encenação; e, 5) intervenções de interpretação transgeracional. Já os insights foram classificados em 1) cognitivo, 2) afetivo e 3) pragmático, de acordo com a proposta de Zimerman (2001) descrita acima.

Como dito na revisão de literatura as duas primeiras categorias de intervenção do terapeuta são derivadas da classificação proposta por Etchegoyen (1987); a primeira intitulada intervenções para obtenção de informações inclui duas subcategorias: assinalamento e confrontação. O assinalamento, refere-se aos momentos em que a terapeuta assinala algo relevante do discurso do paciente, ou seja, lhe chama atenção, com o objetivo de que fique atento à questão e assim ofereça mais informações. Para Fiorini et al. (2004), estas intervenções tensionam o campo levando o paciente a refletir sobre seus pensamentos e sentimentos. Durante a PPB isto apareceu por exemplo no Caso 2, quando a terapeuta assinalou para Helena o comportamento tranquilo do filho na sessão. A mãe contou, então, um

\footnotetext{
${ }^{4}$ Em função do espaço, alguns relatos foram reduzidos, mas sem que isto comprometesse o seu sentido. Na tese de doutorado de Brum (2010) encontram-se outros exemplos.
} 
episódio que ocorreu em casa onde pôde observar que ele também estava tranquilo. É possível inferir na resposta de Helena um insight pragmático, pois ela referiu que mudou seu comportamento com o filho, passando a conversar com ele enquanto fazia as tarefas de casa, o que não acontecia antes:

“-Terapeuta: Tu vê, agora nós conversando aqui, né, tu me contando um monte de coisas tuas, e tal. Ele chega a brincar sozinho ali, viste?

- Helena: Eu peguei e botei ele no colchão lá em casa. Eu passava roupa e falava com ele, ele dava risada. E eu botava os brinquedos e ele brincava. Foi a primeira vez que fiz isto e funcionou. Ele tá mais calmo, mesmo, agora consigo deixar ele mais calmo, porque tô fazendo isto que tu faz de ficar falando com ele."

Foi possível verificar que nas duas famílias o assinalamento gerou um tensionamento fazendo com que a mãe passasse a refletir sobre seus conflitos. As evidências revelaram também que os assinalamentos apresentaram-se associado a insights, o que, a princípio, não seria esperado de acordo com a literatura (Etchegoyen, 1987). Destaca-se também que a intervenção de assinlamento ocorreu nos dois casos atendidos.

A segunda subcategoria denominada intervenção de confrontação, refere-se aos momentos em que a terapeuta destaca no discurso do paciente dois aspectos distintos e contraditórios, com a intenção de colocá-lo ante um dilema, para que note a contradição e, desta forma, possibilite o surgimento de reflexões. Um fragmento de confrontação apareceu no Caso 1, quando Luana falava que sua dificuldade de beijar e abraçar a sua mãe não parecia ter justificativas. Primeiro a terapeuta questionou Luana buscando compreender melhor esta relação mãe-filha. Após a resposta dela, a terapeuta fez uma intervenção de confrontação, buscando conectar o comportamento retraído, que Luana tinha na infância, como correspondente à distância que ela sentia da sua mãe. A intervenção gerou tensionamento e fez com que ela refletisse mais sobre sua relação com a mãe na infância, configurando-se em um insight cognitivo:

“-Terapeuta: Por que tu acha que não tem cabimento?

- Luana: Porque é uma coisa tão simples tu chegar e dar um beijo numa pessoa, dar um abraço.

- Terapeuta: Eu te perguntei, porque, dentro do que tu vivias, tinha o maior cabimento tu ficares assim."
- Luana: Pois é. Pra mim era uma barreira. Tinha o aniversário dela assim, que eu me lembro, e eu não conseguia dar um abraço nela... Às onze horas da noite eu ia dar um abraço nela, porque eu tava me ensaiando o dia inteiro. É verdade, eu tinha mesmo que reagir assim, nunca tinha me dado conta que meu comportamento é uma consequência do dela."

Esta intervenção de confrontação, além de se apresentar associada ao insight cognitivo, fez com que ela passasse a refletir sobre as questões que estavam sendo abordadas na sessão, e aprofundasse sua reflexão (Fiorini, 2004). No presente estudo, a confrontação foi mais usada pela terapeuta, no Caso 1, quando comparado ao Caso 2.

A segunda categoria proposta para análise: intervenções utilizadas para informar o paciente (Etchegoyen, 1987), refere-se às informações oferecidas pela terapeuta ao paciente e inclui três sub-categorias: informação propriamente dita, esclarecimento e interpretação. A primeira subcategoria, denominada de intervenção de informação propriamente dita, refere-se aos momentos em que a terapeuta dá alguma informação ao paciente, que traga elementos para compreender a realidade. Como a situação que aconteceu no Caso 2, quando Helena falava sobre sua preocupação com a saúde do filho e sobre sua agitação, a terapeuta fez intervenções fornecendo informações à mãe sobre a fase de desenvolvimento em que Lucas estava. Helena respondeu, então, que acreditava que o filho não tinha anormalidades, revelando, portanto um insight cognitivo:

“-Helena: Ele é agitado. A gente se envolve com ele o dia inteirinho.

- Terapeuta: Se for olhar assim, um bebê de cinco meses se agita porque ele tá descobrindo o mundo. Ele tá descobrindo, olhando, conhecendo as coisas, isto é normal para um bebê de 5 meses. Imagina ele se fosse bem parado. A gente poderia até pensar que ele não tá podendo olhar pras coisas, ter curiosidade, querer conhecer.

- Helena: Ele conhece tudo. A lotação pára e ele já quer chorar. Ele quer que esteja sempre andando. - Terapeuta: Quer olhar, descobrir, ele gosta do movimento.

- Helena: É! Eu acho que não tem nada de anormal. Ele é uma criança muito agitada. Já é dele mesmo este jeito, isto não quer dizer que seja um problema."

Com relação ao uso desta intervenção, verificou-se que foi pouco presente nos dois Casos. Além disto, 
com base na literatura (Etchegoyen, 1987), esperavase que não apresentasse associação com insights, o que se confirmou no Caso 1, mas não no Caso 2. Acredita-se que esta particularidade deva-se ao fato de que em vários momentos a informação oferecida à mãe do Caso 2 tenha sido significativa, pois referia-se ao desenvolvimento favorável do bebê e estava relacionada a um dos conflitos centrais apresentados por ela, ou seja, sua percepção de ter um filho doente.

A segunda subcategoria, denominada intervenção de esclarecimento, refere-se aos momentos em que a informação da terapeuta está destinada a esclarecer algo que a paciente disse, reordenando a informação. Como no relato do Caso 2 quando Helena conta que Lucas sentia sua agitação, pois quando ele estava no colo da nora ficava tranquilo. Então a terapeuta realizou a intervenção confirmando a percepção dela de que a agitação do bebê advinha do estado emocional em que ela estava. Helena ficou mais consciente que quando ela estava irritada ele ficava agitado. Portanto, Helena teve um insight cognitivo:

"-Helena: Eu acho que o Lucas sente as coisas. Ele vê quando eu tô muito agitada. Porque a criança também fica. Ele não é tranquilo. Eu acho que é por minha causa que ele não é tranquilo. Porque a minha nora pega ele e ele fica calmo no colo dela, e ai ele nem se mexe. Já comigo ele fica mais agitado, eu sou agitada.

- Terapeuta: Então quando tu diz que ele é agitado, tu acha que tem um pouco de ti aí.

- Helena: Tem. Eu acho que tem. É quando eu tô muito irritada dai ele fica agitado."

Com relação à subcategoria intervenções de esclarecimento, encontrou-se que esta se fez presente na maioria das sessões do Caso 1, enquanto no Caso 2 foi pouco presente. Em relação aos insights associados a estas intervenções, encontrou-se também diferenças nos dois Casos investigados. No Caso 1 isto ocorreu na maioria das intervenções, corroborando a ideia de que mesmo quando o paciente tem a informação, por ter sido ele quem a forneceu, nem sempre consegue apreendê-la, captá-la e usá-la. Já no Caso 2, em resposta às intervenções de esclarecimento, a mãe (Helena), na maioria das vezes, concordou com as colocações da terapeuta e, portanto, apresentou pouca associação com insights, o que corrobora as colocações de Etchegoyen (1987), que referiu que este tipo de intervenção, em sua maioria, não promove o insight, por ter a função de deixar mais claro ou ordenar uma informação que já é do paciente.
A terceira subcategoria, denominada intervenção de interpretação, refere-se aos momentos em que a terapeuta oferece uma informação veraz e pertinente ao paciente. Como aparece no relato do Caso 1, apresentado abaixo. A paciente estava falando sobre sua sensação de completude com o filho e de sua falta de desejo sexual e a terapeuta interpretou que o filho poderia estar suprindo muito da vida dela, incluindo o desejo sexual. O conteúdo da resposta da paciente, bem como sua expressão, revelavam afeto, o que configuraria um insight afetivo:

"-Terapeuta: Aí, eu fiquei pensando que é forte isso, né? Que ele supre até o tesão, vamos dizer assim.

- Luana: Uhum... Mas é uma relação de gostar, de amar, né, mas afeta nessa parte, né? É muito forte assim, né? Eu não tenho vontade nenhuma, nenhuma. Chega a me dar arrepio só de falar. Eu, claro, que jamais falo pro meu marido, eu enrolo, não falo pra não magoar, né? A gente transa uma ou outra vez e eu tenho que me esforçar. É um horror!!!

Ainda, em relação a esta subcategoria intervenções de interpretação pode-se dizer que o uso de interpretação nas duas famílias deste estudo, se assemelhou ao da psicanálise clássica, na qual a interpretação estaria no centro da técnica (Freud, 1937/1980). Em termos de uso pela terapeuta a interpretação foi razoavelmente presente nos dois casos atendidos.

A terceira categoria, intervenção de apoio (Barrows, 2003; Winnicott, 1956/2000), refere-se aos momentos em que a terapeuta realiza intervenções que oferecem apoio ao paciente, em relação às suas verbalizações, condutas e/ou sentimentos. Isto pode ser visto em um fragmento do relato do Caso 1, quando a mãe falou que sua irritação em relação às questões da casa e do marido haviam aumentado depois do nascimento do filho. Neste contexto a terapeuta fez uma intervenção de apoio, dizendo à Luana o quanto ela ficou assustada com a proporção que a irritação tomou na sua vida nos últimos tempos. Luana respondeu contando que uma amiga havia passado pela mesma situação que ela.

"-Terapeuta: Tu deve te assustar, né com a irritação? Deve te assustar de onde vem isso...

- Luana: A minha paciência ficou muito menor depois que o Jeferson chegou. Até eu tava conversando com uma colega minha lá, que passou pela mesma situação... igual, igual, ficou mais irritada com o marido e com as coisas da casa..." 
Em relação a esta categoria de análise, apesar de ter se mostrado importante nos atendimentos dos dois casos, parece ter sido mais importante para a mãe do Caso 1 (Luana). Com a mãe do Caso 2 (Helena) ocorreram poucas intervenções desta categoria e a paciente apenas concordou com a colocação da terapeuta. Em relação à mãe do Caso 1 ocorreram intervenções de apoio ao longo de todo tratamento, mesmo que de forma espaçada e algumas apareceram associadas a insights. De modo geral, os achados sobre as intervenções de apoio se apresentaram de forma distinta do esperado. Com base na literatura se esperava que esta categoria fosse mais presente e mais importante em nosso estudo; primeiro porque a própria literatura sobre PPB refere isto (Barrows, 2003; Pollak-Cornillot, 2003) e, segundo, porque as pesquisas em psicoterapia dinâmica breve (Despland et al., 2001), também encontraram que as intervenções de apoio foram mais importantes que as interpretativas no desfecho final do tratamento. É possível se pensar que em função das demandas das mães atendidas neste estudo, elas poderiam estar precisando menos de intervenções de apoio do que os outros tipos de intervenções avaliadas neste estudo, embora também possa contribuir para isto as próprias características da terapeuta.

A quarta categoria, intervenção de encenação (Lebovici, Solis-Ponton, \& Menezes, 1954/2004), refere-se aos momentos em que a terapeuta realiza intervenções dirigidas à mãe e/ou pai falando pelo bebê, ou ainda, quando a terapeuta se dirige diretamente ao bebê enquanto fala aos genitores. Isto pode ser visto no fragmento abaixo envolvendo o Caso 2, quando Helena coloca o filho deitado, mas ele não aceita e a terapeuta realiza uma intervenção de encenação, falando pelo bebê o que ele parece estar querendo mostrar com seu comportamento. Através desta intervenção a terapeuta procura ajudar a mãe a desenvolver sua sensibilidade materna. Contudo, logo após, Helena muda de assunto e diz que lhe falta dinheiro, e sua resposta revela o quanto se sente incapaz de entender o filho. Esta intervenção não se apresentou associada ao insight, pelo menos naquele momento.

\section{“-Bebê: murmura}

- Helena: O que é? Vamos ver se tu brinca melhor aqui. Porque às vezes ele fica melhor deitado. Olha ali.

- Terapeuta: Mamãe eu quero sentar, ó. Não quero ficar deitado... Não dá. Já quero me mexer.

- Helena: Acho que eu vou comprar aquele 'Nenê Dente' que tem, né, tenho que ter dinheiro para isto."
As intervenções de encenação foram muito presentes no atendimento do Caso 2 e pouco no Caso 1 . Além disto, esta intervenção apareceu mais associada com insights no Caso 2, particularmente, insights pragmáticos que estavam relacionados ao desenvolvimento da sensibilidade materna, ou ao seu fortalecimento. Na verdade, nas primeiras sessões a mãe demonstrava pouca sensibilidade materna aos sinais do seu filho, mas a partir da $5^{\mathfrak{a}}$ sessão até a última foi possível perceber uma maior sensibilidade materna. Como o episódio que ocorreu na sexta sessão, quando Helena e a terapeuta conversavam, Lucas começou a mostrar-se incomodado e Helena interpretou que ele queria ser amamentado e ele sugou o seio com vontade. Neste momento a terapeuta falou o quanto Helena estava podendo entender as necessidades do filho. Helena sorriu e disse que antes tinha medo e que agora conseguia entendê-lo.

“-Terapeuta: Ó...

- Helena: Mas eu tô achando que é mamá. Então vamos mamar. Mama o mamá.

- Bebê: choraminga

- Terapeuta: Essa mamãe já tá sabendo tudo, hein? É mamãe, antes tu não sabia o que eu queria. Agora tu sabe que é mamá mesmo o que eu quero. - Helena: Ai, antes eu tinha medo. Agora sim. Agora ele queria teta."

Outro exemplo de encenação associada a um insight pragmático ocorreu na décima sessão quando Lucas se movimentava e Helena observava os movimentos do filho, permitindo que ele os executasse. Neste momento a terapeuta disse que agora Helena estava permitindo que o filho se movimentasse. Helena respondeu não ter mais medo e que por isto estava permitindo que ele se movimentasse.

“-Terapeuta: A mãe também tá deixando eu ir, hein? Se mexer..

- Bebê: faz murmúrios....

- Helena: É, e antes eu tinha medo. Agora já não. Agora não. Agora ele já se firma, também, mais um pouquinho. Daí eu não tenho... Eu deixo.

- Bebê: fala."

Desta forma, pode-se dizer que para este caso, ao final do tratamento já aparecia um claro aumento da sensibilidade materna, indicando a importância da intervenção de encenação, por ter sido a que mais conduziu à mudanças. Além disto, estes resultados corroboram a literatura sobre o impacto da PPB no aumento da sensibilidade materna (Cramer et al, 1990; Gomes, 2007). 
Por fim, a quinta categoria, intervenção de interpretação transgeracional (Barrows, 2003; Fraiberg et al., 1994; Lebovici, 1993), refere-se aos momentos em que a terapeuta realiza interpretações dos processos transgeracionais, juntando-os com os conteúdos trabalhados no aqui-e-agora da sessão. Isto pode ser visto no relato do Caso 1, no qual Luana contava que a mãe trabalhava o tempo todo em casa, lavava e passava para fora e cuidava dos filhos de uma vizinha, para assim poder ficar em casa e ao mesmo tempo ganhar algum dinheiro que ajudasse no sustento da família. Contudo, ela ressalta a distância física da mãe e após também revela que sua mãe era distante afetivamente. Neste contexto a terapeuta realizou uma interpretação transgeracional, buscando conectar o presente, a relação simbiótica de Luana com o filho, com a ausência afetiva de sua mãe no passado, e desta forma, Luana procurava dar ao filho a atenção, que gostaria de ter recebido de sua mãe:

“-Terapeuta: A gente tava falando dessa coisa assim, de como é que foi a tua infância... Eu quero te dizer da falta que tu pode ter sentido desta relação de proximidade com a tua mãe.

- Luana: Sim, claro.

- Terapeuta: Mas pra compreender porque hoje pra ti é tão primordial, uma vontade de ter com o Jeferson uma coisa muito diferente, ... Como se o Jeferson fosse um pouco tu assim. Dar pro Jeferson tudo que tu talvez quisesse, sabe ter recebido?

- Luana: Pois é. Isso é claro assim, de não fazer esse tipo de coisa com ele, né? É, procuro fazer bem diferente do que minha mãe fazia comigo."

Neste exemplo Luana parece compreender cognitivamente a interpretação da terapeuta, entretanto, o insight pragmático eventualmente associado a esta interpretação apareceu bem depois $\left(13^{\circ}\right.$. sessão) quando Luana revelou para a terapeuta que as tarefas de casa não a irritavam mais, pois estava conseguindo dar conta delas e do filho, por acreditar que não precisava mais largar tudo para atendê-lo. Diante da pergunta da terapeuta sobre o motivo de não precisar largar tudo para atender o filho, Luana respondeu que entendeu que antes largava tudo pelo medo de ser uma mãe igual a sua mãe:

“-Terapeuta: Por que tu acha que hoje tu não está mais precisando largar tudo para atender o Jeferson?

- Luana: Eu entendi que eu largava tudo com medo de ficar uma mãe igual a minha mãe, e agora sei que não sou igual a ela, estou mais tranquila com isto e também sei que ele pode esperar, que não é o fim do mundo, antes achava que era."

No Caso 2 encontrou-se poucas intervenções de interpretação transgeracionais e nenhuma delas apresentou associação com insights. Já no Caso 1, quando comparado ao 2, esta intervenção foi mais presente e pareceu ter sido mais importante por ter apresentado alguma associação com insights, inclusive do tipo pragmático.

\section{Considerações finais}

Os resultados do presente estudo revelaram que as intervenções de interpretação, esclarecimento e encenação estiveram associadas às mudanças ocorridas com as participantes deste estudo. Neste sentido, para estas mães estas intervenções devem ser consideradas como importantes fatores específicos no tratamento em psicoterapia pais-bebê. Contudo, destacamos que as demais intervenções (apoio, assinalamento, confrontação, informação propriamente dita e interpretação transgeracional) também contribuíram para o processo terapêutico, principalmente nas situações em que as mudanças decorreram do uso de um conjunto de intervenções e não apenas de uma intervenção específica. Além disto, cabe destacar que a terapeuta provavelmente adequou sua forma de intervir para se ajustar ao funcionamento de cada família (Ferreira et al., 2015).

É notório comentar que mesmo no contexto de psicoterapia psicodinâmica breve com adultos, o estudo de Despland et al. (2001) revelou que, das categorias de intervenção do terapeuta avaliadas (interpretativas, apoio e definições oferecidas pelo terapeuta), nenhuma delas isoladamente influenciou o desfecho final investigado. Neste sentido, como postularam Cramer e Palácio-Espasa (1993), as intervenções em PPB se assemelham, em sua maioria, às utilizadas na técnica da psicanálise clássica ou da psicoterapia psicanalítica, com exceção da intervenção de encenação que é mais específica da PPB. Ou ainda como referiu PollakCornillot (2003), na prática junto a bebês e pais, é indispensável que sejam respeitadas as regras sobre as quais se baseia o caráter psicanalítico do tratamento. Podemos ainda ponderar que estes resultados podem estar expressando a forma como foi realizada a análise dos casos com base nas formulações de PPB propostas por Cramer e Palácio-Espasa (1993), que direcionam mais as intervenções à mãe, quando comparado a outras propostas de PPB, como a de Alicia Lieberman (cf. Guedeney et al., 2016), por exemplo, que inclui mais o bebê na sessão psicoterápica. 
Uma das questões relevantes da proposta metodológica apresentada neste artigo refere-se à tentativa de avaliar os fatores específicos de mudança em PPB. Comumente as pesquisas em psicoterapia apontam que são os fatores inespecíficos que têm aparecido associados com mudanças positivas ao longo do processo terapêutico (Mander et al., 2017; Björnsson, 2015; Tschuschke et al., 2015) e, dentre estes, o que tem sido destacado com mais frequência se refere à interação paciente e terapeuta. Com isto, alguns autores tem enfatizado que é a qualidade da relação terapêutica o fator crucial de mudança, e menos importância é dada para fatores específicos da técnica. Contudo, Cramer e Palácio-Espasa (1993) destacaram a necessidade de que pesquisas sobre PPB avaliassem a influência de fatores específicos nas mudanças apresentadas pelas díades e, destacaram a importância de avaliar as intervenções do terapeuta, particularmente, o efeito do uso de interpretações nos processos de mudança. Apesar desta sugestão ter sido feita há bastante tempo, não se encontrou estudo que atendesse a sugestão destes autores. Portanto, a utilização de uma metodologia específica para analisar as intervenções do terapeuta segue ausente na literatura que aborda a temática da PPB, e o presente trabalho buscou contribuir para atender a esta demanda. De qualquer modo são necessários muitos outros estudos sobre o processo de psicoterapia pais-bebê para se avançar na compreensão desta abordagem e, especialmente, para avaliar a extensão com que as categorias propostas no presente estudo são úteis no entendimento das intervenções e especialmente de sua associação com os insights.

\section{Referências}

Alfaya, C (2006). O comportamento exploratório de bebês e o comportamento de mães com indicadores de depressão durante uma psicoterapia breve mãe-bebê. Tese, PPG Psicologia, UFRGS.

Barrows, P. (2003). Change in parent-infant psychotherapy. Journal of Child Psychotherapy, 29(3), 283-300. https:// doi.org/10.1080/00754170310001625396

Beutler, Larry (2013). Common, specific, and cross-cutting psychotherapy interventions. Psychotherapy: theory, research and practice, 50(3), 298-301. https://doi.org/10.1037/a0032405

Bion (1962). Aprendendo com a experiência. Rio de janeiro: Imago.

Björnsson, A. (2015) Experimenting with Psychotherapy. Nordicum-Mediterraneum, 9(2), 1-8.

Brum, E. (2010). Psicoterapia Pais-Bebê no Contexto da Depressão Pós-Parto: Investigando o processo psicoterápico. Tese, PPG Psicologia, UFRGS.

Cassel, P., Sanchez, L., Campezatto, P., \& Tiellet-Nunes, M. (2015). Processo psicoterapêutico: compreensão de momentos de mudança psicológica em uma sessão de psicoterapia psicanalítica. Contextos Clínicos, 8(1), 27-37. https://doi.org/10.4013/ctc.2015.81.03

Chinitz, et al. (2017) Improving outcomes for babies and toddlers in child welfare: A model for infant mental health intervention and collaboration. Child Abuse \& Neglect, 70, 190-198. https://doi.org/10.1016/j.chiabu.2017.05.015

Cramer, B. \& Stern, D. (1988). Evaluation of chances in mother-Infant brief psychotherapy: a single case study. Infant Mental health, 9(1), 20-45. https://doi.org/10.1002/1097-0355(198821)9:1<20::AID-IMHJ2280090105>3.0.CO;2-E

Cramer, B., Robert-Tissot, C., Stern, D., Serpa-Rusconi, S., Mural, B., Besson, G., Palacio-Espasa, F., Bachmann J., Knauer, D., \& D'arcis, U. (1990). Outcome evaluation in brief mother-infant psychotherapy: A preliminary report. Infant Mental Health Journal, 11(3), 278-300. https://doi.org/10.1002/1097-0355(199023)11:3<278::aidimhj2280 $110309>3.0 . c 0 ; 2-h$

Cramer, B. \& Palácio-Espasa (1993). Técnicas psicoterápicas mãe-bebê. POA: Artmed.

David, P. \& Schiff, M. (2015). Learning from bottom-up dissemination: Importing an evidence-based trauma intervention for infants and young children to Israel. Evaluation and Program Planning, 53, 18-24. https://oi. org/10.1016/j.evalprogplan.2015.07.012

Despland, J., Roten, Y., Despers, J., Stigler, M., \& Perry, J. (2001). Contribution of patient defense mechanism and therapist intervention to the development of early therapeutic alliance in a brief psychodynamic investigation. Journal of Psychopherapy Practice and Research, 10: 155-164.

Etchegoyen, H. (1987). Fundamentos da técnica psicanalítica. Porto Alegre: Artes Médicas.

Ferreira, J. et al. (2015). Exploring Phase Progression Throughout the Therapeutic process: The Case of Eva. Clinical Psychology and Psychotherapy, 23(5), 407-424. https://doi.org/10.1002/cpp.1970

Fiorini, H. (2004). Teoria e Técnica de Psicoterapias. São Paulo: Martins Fontes.

Fishman, D. (2000). Transcending the efficacy X effectiveness research debate: proposal for a new, electronic "Journal of Pragmatical Case Studies". Prevent \& Treatment, 3(8), 1-25. https://doi.org/10.1037//1522-3736.3.1.38a

Fonagy, P., Sleed, M., \& Baradon, T. (2016). Randomized controlled trial of parent-infant psychotherapy for parents with mental health problems and young infant. Infant Mental Health Journal, 37(2), 97-114. https://doi.org/10.1002/ imhj. 21553 
Fraiberg, S., Adelson, E., \& Shapiro, V. (1994). Fantasmas no quarto do bebê: uma abordagem psicanalítica dos problemas que entravam a relação mãe-bebê. Revista do CEAPIA, 7(7), 12-35.

Freud. (1937). Construções em análise. In Obras psicológicas completas de Sigmund Freud (Vol. XIII). Rio de Janeiro: Imago, 1980.

Frizzo, G. (2008). Contribuições da psicoterapia breve pais-bebê para a conjugalidade e para a parentalidade em contexto de depressão pós-parto. Tese, PPG Psicologia, UFRGS.

Gomes, A. (2007). Malformação do bebê e maternidade : impacto de uma psicoterapia breve pais-bebê para as representações da mãe. Tese PPG, UFRGS.

Goldfried, M. \& Wolfe, B. E. (1996). Psychotherapy practice and research: repairing a strained alliance. American Psychologist, 51(10), 1007-1016. https://doi.org/10.1037//0003-066X.51.10.1007

Goodman, Jh., Prager, J., Goldstein, R., \& Freeman, M. (2015). Perinatal Dyadic Psychotherapy for postpartum depression: a randomized controlled pilot trial. Archives Of Womens Mental Health, 18(3): 493-506. https://doi. org/10.1007/s00737-014-0483-y

Guedeney, A. (2016). Treatment - Mother-infant relationship psychotherapy. Best Practice \& Research Clinical Obstetrics and Gynaecology, 28, 135-145. https://doi.org/10.1016/j.bpobgyn.2013.08.011

King, K., Priddis, L., \& Kane, R. (2014). Enhancing Maternal Sensitivity and Emotional Wellbeing Through a Preventative Parent - Child Relationship Intervention in a Community Setting. Journal of Child and Family Studies, Springer. https://doi.org/10.1080/00754170310001625404

Lebovici, S. (1993). On intergenerational transmission: from filiation to affiliation. Infant Mental Health Journal, 14(4), 260-272. https://doi.org/10.1002/1097-0355(199324)14:4\%3C260::aid-imhj2280140402\%3E3.0.co;2-Z

Lebovici, S., Solis-Ponton, L. \& Menendez, J. (2004). A árbore da vida ou a empatia metaforizante, o enactment. In L. Solis-Ponton. Ser pai e ser mãe parentalidade: um desafio para o terceiro milênio - uma homenagem internacional a Serge Lebovici (pp. 41-46). São Paulo: Casa do Psicólogo. (Original published in 1995).

Lenze, Sn., Rodgers, J., \& Luby, J. (2015). A pilot, exploratory report on dyadic interpersonal psychotherapy for perinatal depression. Archives Womens Mental Health, 18(3), 485-491. https://doi.org/10.1007/s00737-015-0503-6

Mander, J. et al. (2017). The therapeutic alliance in different mental disorders: A comparison of patients with depression, somatoform, and eating disorders. Psychology and Psychotherapy: Theory, Research and Practice, 90(4), 649-667. https://doi.org/10.1111/papt.12131

Pollak-Cornillot, M. (2003). Thérapie brève mere-nourrisson et utilization psychanalytique d'enregistrements video. In C. Auzieu-Premmereur \& M. Pollak-Cornillot. Les pratiques psychanalytique auprès des bebés (pp. 237-271) Paris: Dunod.

Prout, T. et al. (2017). A Expert Clinicians' Prototype of an Ideal Treatment in Regulation-Focused Psychotherapy for Children (RFP-C). Journal of Psychotherapy Integration. https://doi.org/10.1037/int0000102

Puura K, Kaukonen P. (2010). Parent infant psychotherapies and indications for inpatient versus outpatient treatments. In S. Tyano, M. Keren, H. Herrman et al., editors. Parenthood and mental health. A bridge between infant and adult psychiatry (pp. 401-414). Oxford: Wiley-Blackwell. https://doi.org/10.1002/9780470660683.ch35

Sandell, R. (2015). Rating the outcomes of psychotherapy or psychoanalysis using the Change After Psychotherapy (CHAP) scales. Manual and commentary. Research in Psychotherapy: Psychopathology, Process and Outcome, 18(2), 32-49. https://doi.org/10.7411/RP.2015.111

Salomonsson, M. W., Sorjonen, K., Salomonsson, B. (2015). A long-term follow-up study of a randomized controlled trial of mother-infant psychoanalytic treatment: outcomes on mothers and interactions. Infant Mental Health Journal, 36(6), 542-55. https://doi.org/10.1002/imhj.21536

Salomonsson, B (2017). The function of language in parent-infant psychotherapy. Int J Psychoanal, 98(6), 1597-1618. https://doi.org/10.1111/1745-8315.12666

Silva, M. (2007). Paternidade e Depressão Pós-parto Materna no Contexto de Uma Psicoterapia Breve Pais-Bebê. Tese, PPG Psicologia, UFRGS.

Stake, R. E. (2006). Multiple case study analysis. The Guilford Press, New York.

Toth, S., Sturge-Apple, M., Rogosch, F., \& Cicchetti, D. (2015). Mechanisms of change: Testing how preventative interventions impact psychological and physiological stress functioning in mothers in neglectful families. Dev Psychopathol, 27(4), 1661-1674. https://doi.org/10.1017/S0954579415001017

Tschuschke, V. et al. (2015). The role of therapists' treatment adherence, professional experience, therapeutic alliance, and clients' severity of psychological problems: Prediction of treatment outcome in eight diferente psychotherapy approaches. Psychotherapy Research, 25:4, 420-434, https://doi.org/10.1080/10503307.2014.896055

Valdés, N., Krause, M., Vilches, O., Dagnino, P., Echavarri, O., Bem-Dov, P., \& Arístegui, R. (2005). Proceso de cambio psicoterapéutico: análisis of relevant episodes in a group therapy with addict patients. PSYKHE, 14(2), 3-18. https:// doi.org/10.4067/S0718-22282005000200001

Zimernan, D. (2001). Vocabulário contemporâneo de psicanálise. Porto Alegre: Artes Médicas.

Waldron, S. et al. (2015). Do the Processes of Psychoanalytic Work Lead to Benefit? Studies by the APS Research Group and the Psychoanalytic Research Consortium, Psychoanalytic Inquiry: A Topical. Journal for Mental Health Professionals, 35(1), 169-184, https://doi.org/10.1080/07351690.2015.987602 
Winnicott, D. (2000). Preocupação materna Primária In D. Winnicott. Da pediatria à psicanálise: obras escolhidas (pp. 399-405). Rio de Janeiro: Imago (Original Published in 1956).

Dados dos autores:

Evanisa Helena Maio de Brum - Pós-Doutora, Universidade Federal do Rio Grande do Sul e Centro Universitário Cesmac.

Aline Grill Gomes - Doutora, Universidade Federal do Rio Grande do Sul e Sociedade Psicanalítica de Porto Alegre - SPPA.

Cesar Augusto Piccinini - Pós-Doutor, Universidade Federal do Rio Grande do Sul.

Endereço para correspondência:

Evanisa Helena Maio de Brum

Rua Durval Guimarães, 900 apto 702

57035060 Maceió, AL, Brasil

$<$ Evanisa.brum@gmail.com>

Recebido em: 22.08 .2017

Aceito em: 28.08.2018 